\title{
Influence of Moringa Leaves Extract on Hb Response to Radiation Dose Rates' Changes: I. Permittivity and Its Thermodynamic Driven State Functions
}

\author{
Mohamed M. M. Elnasharty 1,* (D), Azhar M. Elwan ${ }^{2}$ \\ 1 Microwave Physics and Dielectrics Dept., National Research Centre (NRC)-33 El Bohouth St., Dokki, 12622-Giza, Egypt; \\ mohamed.elnasharty@gmail.com (M.M.M.E.); \\ 2 Biochemistry Dept., National Research Centre (NRC)-33 El Bohouth St., Dokki, 12622-Giza, Egypt; \\ z.mahmoud2006@gmail.com (A.M.E.); \\ * Correspondence: mohamed.elnasharty@gmail.com;
}

Scopus Author ID 55929231300

Received: 15.03.2021; Revised: 12.04.2021; Accepted: 16.04.2021; Published: 26.04.2021

\begin{abstract}
The harm caused by ionizing radiation is well known and is performed by depositing energy from the radiation source into the irradiated material. Biosystems fight back to maintain their integrity and functions. Doing so requires external help where important supplements are provided to enable the biosystem to challenge destruction done by irradiation in the form of ionization and free radicals. This work investigates the effect of Moringa oleifera leaves extract, MOLE, on two different gamma radiation dose rates' damages on the biosystem. This is done by estimating physical parameters that belong to dielectric factors, static permittivity, or based upon them as thermodynamic state functions; changes in Helmholtz free energy, internal energy, and entropy of the sample under assessment. Good sensitivity to factors causing changes in the studied system's net dipole moment is noticed, especially within the $1^{\text {st }}$ week. The help of MOLE, a natural supplement, to the biosystem repairing the damage caused by irradiation was tested. Data indicated that MOLE has a powerful influence that could help the biosystem, based on its vast nutrients, trace elements, and antioxidants to fight radiation damage.
\end{abstract}

Keywords: Moringa leaves extract; irradiation dose rate; permittivity; thermodynamic state functions; mortality rate.

(C) 2021 by the authors. This article is an open-access article distributed under the terms and conditions of the Creative Commons Attribution (CC BY) license (https://creativecommons.org/licenses/by/4.0/).

\section{Introduction}

For ages, medical plants are used for protection and treatment from several diseases. Moringa oleifera is one of these medical plants that are found in many countries such as China, Egypt, India, and Nigeria [1-4]. Among the Moringa parts (roots, seeds, leaves, and flowers), the most nutritive part is the leaf. The leaf has essential and nonessential amino acids such as lysine, histidine, methionine, cysteine, glycine, vitamins as thiamine, riboflavin, and niacin, and minerals like magnesium, potassium, calcium, zinc, iron, and copper. So, it was found that the Moringa leaf has anti-inflammatory, anti-tumor, antioxidant, anti-fungal, antibacterial, and anticancer activities. In addition to the ability of Moringa leaves to help the biosystem overcoming several diseases such as ulcer, diabetes, hypertension, hepatotoxicity, and obesity [5-20].

Moringa oleifera leaves extract (MOLE) can also act as a radioprotector [21-24]. Therefore, in this study, the extract was suitable for the therapy or decrement of high acute dose effects of gamma radiation. In addition, it would increase the information wealth about 
this plant to compare its effects in case of relatively higher and lower dose rates of irradiation for a single acute dose.

Ionizing radiation is used as radiotherapy for killing cancer cells, but exposure to high doses of ionizing radiation can cause damage to the normal cells. Using lower dose rates for the same high dose may reduce the damage of cells relatively as a result of repair occurs within the long irradiation time, which leads to lower cytotoxicity [25-33].

In this work, applying the effect of MOLE on irradiated hemoglobin molecule, $\mathrm{Hb}$, is so significant, where $\mathrm{Hb}$, a metalloprotein carried inside the red blood cells, has great importance in the body as it helps red blood cells, RBCs, to transport oxygen from lung to tissues and transport $\mathrm{CO}_{2}$ from tissues to the lung. It can also preserve the shape of RBCs. $\mathrm{Hb}$ contains four subunit chains of protein; each subunit holds a heme group which consists of an iron atom connected to the porphyrin ring $[34,35]$.

The use of dielectric and thermodynamic is essential in science and medicine as to probe and interpret the data which are sensitive to dipolar changes within the sample, so it can be used to measure the changes in the nervous system, heart, muscles, and also the cancer cells [36-39].

The physical parameters used in this work have proved not only the ability to detect and follow up the biosystem status after irradiation, but also they could show distinct differences in the biosystem reaction to different dose rates of irradiation even in case of the use of the same total dose [29, 30, 40,41]. To initiate such analysis, one must perform a dielectric sweep to the molecule of interest versus frequency. The next step is to search the dielectric spectrum for molecular relaxation belongs to the molecule. There are two possibilities (i) there isn't any relaxation within the available frequency window; analysis will be restricted to comparing values of various dielectric parameters and their behavior under different conditions. (ii) There is one or more dipolar relaxation related to the molecule; in this case, dielectric analysis must be performed to the found relaxation(s) for various experiment probabilities at a suitable temperature range with suitable temperature steps. Consequently, the researcher can start interpretation of dielectric data obtained. Finally, there can be two further steps to add; the $1^{\text {st }}$ uses the Multiphysics essence to add more joy to the work where one can transfer the obtained dielectric data into a thermodynamic world. The $2^{\text {nd }}$ step is to analyze and interpret the final thermodynamic data together with the dielectric one. This is how researchers can dive into the biosystem using Multiphysics tools.

Exploring the dielectric data of $\mathrm{Hb}$ molecule reveals high conductivity that masks dipolar relaxations that could be present within the measured frequency window. In such a case, one would look at the modulus-frequency spectrum, and if a dipolar relaxation were found, equations (1) are then used to analyze and fit data. Fitting data will provide the value of the static permittivity of such relaxation.

$$
M^{*}(\omega)=\varepsilon_{s}^{-1}-\frac{\varepsilon_{s}^{-1}}{\left(1+\left(i \omega \tau_{\sigma}\right)^{\alpha}\right)^{\beta}}
$$

Where, $\alpha$ and $\beta$ are shape parameters, $\tau_{\sigma}$ is the dc conductivity relaxation time, $\omega$ is the angular frequency, $i$ is the root mean square of $\sqrt{ }-1$.

Static permittivity is then used to relate the dielectric spectroscopy to some thermodynamic state functions by the following equations [42,43]. Logging into the thermodynamic world permits the arrival of another set of information that could be more informative about the system than the static permittivity itself. 
The permittivity-related thermodynamic state functions $\Delta \mathrm{F}, \Delta \mathrm{U}$, and $\Delta \mathrm{S}$ describe the change in Helmholtz free energy, internal energy, and the degree of $\mathrm{Hb}$ disorder changes molecule, respectively. All of these functions have the merit that they are independent of the root led to that status.

$$
\frac{\Delta F}{E^{2}} \equiv \frac{F(T, E)-F_{O}(T)}{E^{2}}=\frac{\varepsilon_{o}}{2} \varepsilon_{S}
$$

Where, $F(T, E), F_{o}(T)$, are the Helmholtz free energies as functions of temperature, $T$, when the electric field, $E$, is switched on or off respectively and $\varepsilon_{o}$ is the permittivity of free space.

$$
\frac{\Delta U}{E^{2}} \equiv \frac{U(T, E)-U_{o}(T)}{E^{2}}=\frac{\varepsilon_{o}}{2}\left(\varepsilon_{S}+T \frac{\partial \varepsilon_{S}}{\partial T}\right)
$$

Where, $U(T, E), U_{o}(T)$, are the internal energies as functions of temperature, $T$, in the presence and absence of the applied $E$.

$$
\frac{\Delta S}{E^{2}} \equiv \frac{S(T, E)-S_{O}(T)}{E^{2}}=\frac{\varepsilon_{o}}{2} \frac{\partial \varepsilon_{S}}{\partial T}
$$

Where, $S(T, E), S_{o}(T)$, are the entropies as functions of temperature, $T$, in the presence and absence of electric field [40-45].

Knowledge of the status of the molecule or biosystem understudy at different stages of the experiment provides important information to the researcher, at least, about both damage and the strength of repair mechanisms toward each effector investigated. Knowing the energy available for building up processes would recommend favors, certain processes over others depending on the amount of energy required for such processes. Change in Helmholtz free energy provides this information. Awareness of the degree of disorder within the investigated system would indicate the strength of force applied by the effector on the system of interest, and the entropy change provides this. On the other hand, the internal energy change can provide us with information about the system components and interactions among them under the force of the effector used.

This research aims to introduce a new perspective by using Physics and physical factors to measure the $\mathrm{Hb}$ molecule and use it as a biomarker that detects damage at the physical stage. This is very important as recognizing the damage at this stage permits a proper medical intervention for individual cases separately. Then, it minimizes the damage before it develops into the biochemical or biological stage at which there is no turning back.

\section{Materials and Methods}

\subsection{Plant material.}

Local Egyptian Ethanolic Moringa oleifera leaves extract, MOLE, was bought from the Association of Moringa, Agricultural Division, NRC, and was prepared according to the method of Suhartono et al. [46]. The dose of extract that was administered to animals per day was $1 \mathrm{~g} / \mathrm{kg}$.

\subsection{Experimental animals.}

Adult Wistar female albino rats (120-150g) were kept in rat polypropylene cages at a temperature $\left(25 \pm 3^{\circ} \mathrm{C}\right)$. Experimental animals and protocol complied with Medical Research Ethics Committee 2003 (MREC, 2003). 


\subsection{Experimental design.}

Wistar rats (86) were divided into two main groups. The first group (40 rats) was irradiated with an acute dose $(7.0 \pm 0.03 \mathrm{~Gy})$ of gamma radiation at a higher dose rate, HDR, $533.350 \mathrm{mGy} / \mathrm{min}$, and then treated with Moringa extract $(1 \mathrm{~g} / \mathrm{kg})$ orally for 15 days postirradiation, and its control, C HDR, ( 8 rats). The second group (30 rats) was irradiated with the same radiation dose at a lower dose rate, LDR, $325.89 \mathrm{mGy} / \mathrm{min}$ and then treated with MOLE by the same way, its control, C LDR, (8 rats). Both irradiated groups were followed up for two weeks after stopping the administration of MOLE. The animal's number was increased to 40 in HDR group as the probability of animals' mortality was higher in this case. The terminology used for both groups, HDR and LDR, is relative to differentiate each group as both dose rates used are high.

\subsection{Irradiation condition.}

The irradiation process in the National Institute of Standards (NIS) was recognized as a secondary standard ionizing metrology Laboratory. Rats were irradiated using ${ }^{60} \mathrm{Co}$ as a $\gamma$ radiation source, having a built-in Thermatron system, at $20^{\circ} \mathrm{C}$, under an atmosphere of air. Secondary standard dosimetry system of $0.6 \mathrm{cc}$ ionization chamber coupled with electrometer calibrated at BIPM, 2012 used to measure dose rate. Two dose rates were used 533.350 and $325.89 \mathrm{mGy} / \mathrm{min}$, to reach a total dose of $7.0 \pm 0.03 \mathrm{~Gy}$ at $1 \mathrm{~m}$ from the source for both irradiated groups.

\subsection{Sample preparation.}

Animals were sacrificed, and blood is collected within a heparinized tube. After removing plasma and washing 3-5 times using $0.9 \% \mathrm{NaCl}$ saline solution, an equal amount of cold distilled water to that of the packed RBCs is added. Then the tube containing both the $\mathrm{RBCs}$ and distilled water is centrifuged at $10,000 \mathrm{rpm}$ at $4^{\circ} \mathrm{C}$ for 30 minutes [47]. Finally, we can collect the supernatant, $\mathrm{Hb}$ solution.

\subsection{Instruments and measurement.}

Dielectric measurements were achieved by an impedance analyzer (E4991B) from KeySight Co., USA, in the frequency range $\left(10^{6}-3 \times 10^{9} \mathrm{~Hz}\right)$. Using a homemade measuring cell is composed of two brass electrodes diameter $8 \mathrm{~mm}$ and a Teflon cylinder. A homemade compartment (patent no. 28776/2018) was also designed to hold the measuring cell and maintain the cell at the desired temperature during the measurement.

\section{Results and Discussion}

In Fig. $1 \mathrm{~A}$ and $\mathrm{B}$, the modulus relaxation extending from about $10^{6} \mathrm{~Hz}$ to $3 \times 10^{8} \mathrm{~Hz}$, Fig. 1A. Due to the massive conductivity of the $\mathrm{Hb}$ solution resulting in very high permittivity, $\varepsilon^{\prime}$, and loss, $\varepsilon^{\prime \prime}$, values which are expected for biological samples. The displayed relaxation was analyzed, Fig. 1B, using the complex formula of $\mathrm{HN}$ modulus equation (1) to estimate the values of the static permittivity, $\varepsilon_{s}$. The latter is used for comparison and to calculate related thermodynamic state functions. 


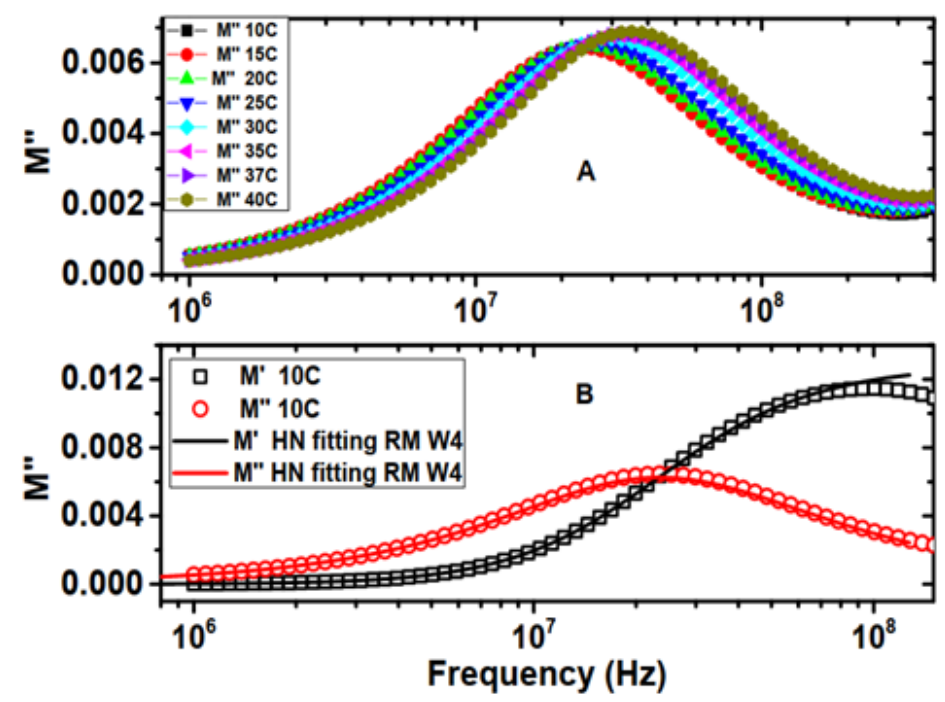

(a)

Figure 1. Modulus relaxation (A) and an example of fitting (B).

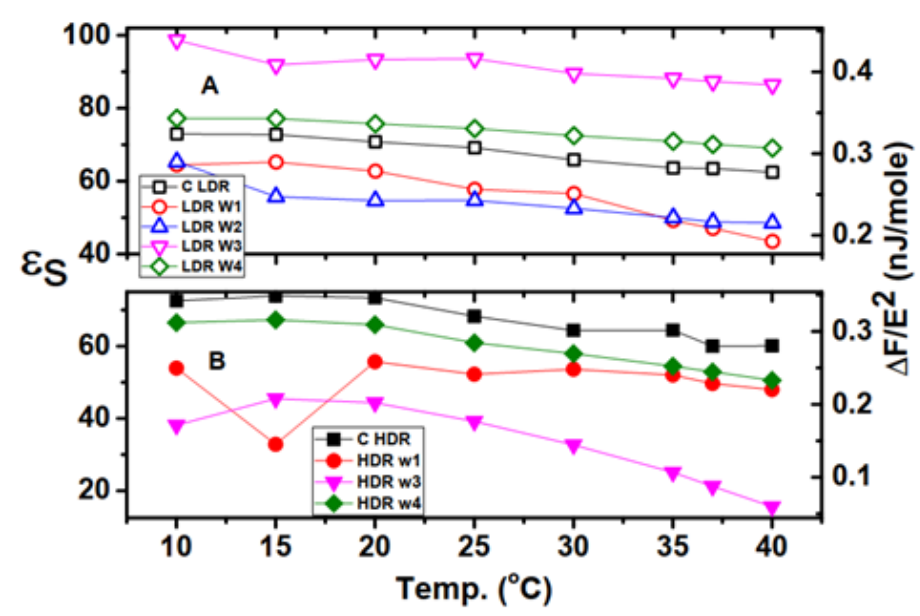

Figure 2. A and B) displays the permittivity and Helmholtz free energy as functions of temperature for LDR (A) and $\operatorname{HDR}(\mathrm{B})$.

The HDR, Fig. 2B, shows a descendence of permittivity and free energy levels detected in the first week, which ran down further in the 3rd week then rises up to become near the control level. LDR, Fig. 2A, decreases the first and second weeks in the values of permittivity and free energy followed by a high upswing above the control, which falls toward the latter in the fourth week. Because the use of these physical parameters for the current purpose is relatively new and qualitative, authors verified the influence of Moringa oleifera leaves extract by comparing the results to references [29, 40], where the results based on the same experimental setup in the absence of Moringa administration under the same conditions. As for HDR, the $1^{\text {st }}$ and $2^{\text {nd }}$ weeks had values higher than that of the control while the $3^{\text {rd }}$ and $4^{\text {th }}$ weeks had similar values to the control, i.e., the Moringa leaves extract caused a general decrease in the permittivity and Helmholtz free energy of the $\mathrm{Hb}$ molecule. On the other hand, in LDR the impact of Moringa leaves extract was limited to a decrement of the second-week levels of both parameters and a relative increase in the 1st week level of the permittivity and free energy, however still below the control level. 


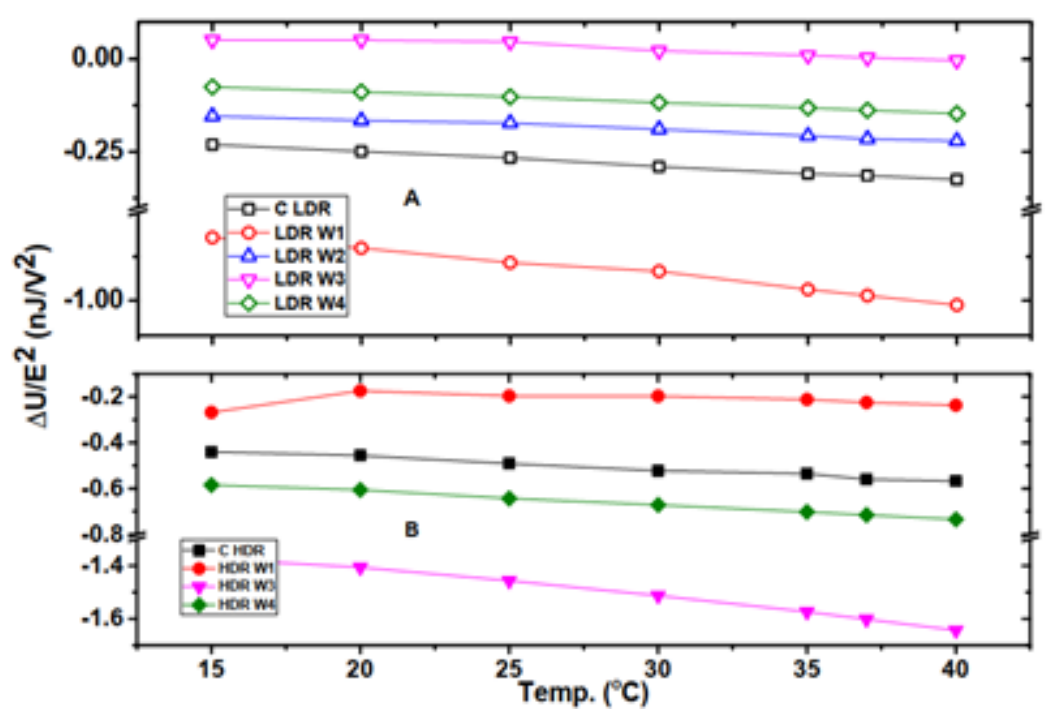

Figure 3. Change of the internal energy with temperature along one month after irradiation in LDR, A, and HDR, B, of which Moringa leaves extract was administrated in the first two weeks for both groups.

HDR, Fig. 3B, caused a higher internal energy level in the $1^{\text {st }}$ week and a steep decrease in the third week, followed by a rise that makes the $4^{\text {th }}$ week's internal energy approaches control values. LDR, Fig. 3A, produced lower internal energy in the $1^{\text {st }}$ week and an escalation above the control values in the $2^{\text {nd }}$ week, followed by another climb reaching its peak in the third week then started descending in the $4^{\text {th }}$ week. These results, except for the $1^{\text {st }}$ week for both HDR and LDR, are in contrast to references [29, 40] which explain the effect of Moringa oleifera leaves extract. The latter in the HDR was decreasing the internal energy levels below the control values except for the first week. Its effect on the LDR was to increase the internal energy levels above that of the control for all weeks except for the $1^{\text {st }}$ week as well. In short, the Moringa leaves extract administration counteracted the radiation effects in both HDR and LDR.

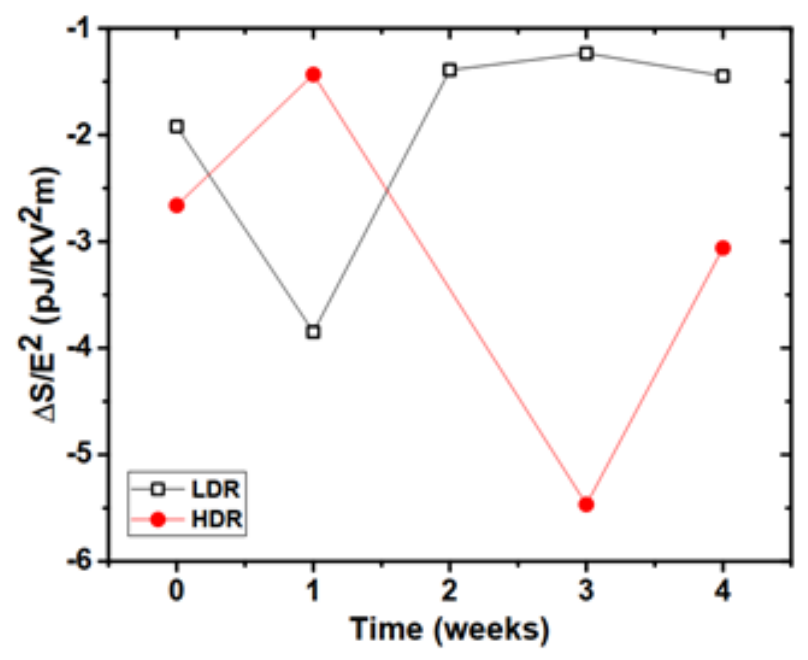

Figure 4. Entropy change of LDR and HDR groups during four weeks, experiment time.

Fig. 4 Illustrates the entropy change in the HDR group records an increase on the Yaxis in the $1^{\text {st }}$ week followed by a steep decrement in the $3^{\text {rd }}$ week then approaches control in the fourth week. A mild decrease of the entropy change within the LDR group in the $1^{\text {st }}$ week reversed to an increment that stabilized from the $2^{\text {nd }}$ to the $4^{\text {th }}$ weeks. Again, we notice that the HDR group succeeds in approaching the control values, whereas the LDR one could not within the experiment time, which agrees with previous work [29, 30, 40]. It is noticed that the entropy 
change had almost the same values for both groups, HDR and LDR, in the $1^{\text {st }}$ week implying irradiation effect was dominant compared to the Moringa leaves extract on the entropy during the $1^{\text {st }}$ week after irradiation. However, Moringa leaves extract not only overwhelms the radiation effect but also enables the biosystem to reverse it during the rest of the month, experiment time, even though it was administrated for just two weeks after irradiation to the LDR group. The latter conclusion was founded on current data and the results of the entropy change response to the same dose rates without any additional supplements given to the irradiated animals [40].

By designing such an experiment, we intended to investigate two goals; the $1^{\text {st }}$ is to test the ability of the dielectric and thermodynamic parameters, and pick up the best of them, to be used as biophysical factors, markers to diagnose and/or prognose the biosystem status, that would have a faster and accurate response to an effector that disturbs the electrical homogeneity of the biosystems. The $2^{\text {nd }}$ aim was to assess the Moringa leaves extract as an inexpensive natural supplement that can help the biological systems repair the irradiation damage. Upon these objectives, two roots were followed cellular and molecular. The current work is concerned with the molecular as it inspects the $\mathrm{Hb}$ molecule, which we expected to be the least affected by Moringa leaves extract administration. This expectation was based on some thoughts that the $\mathrm{Hb}$ is a molecule. Its response to the natural supplement would be less than the cells. The response would be mostly the replacement of the damaged molecules, and that would not be measurable by the planned parameters. Unexpectedly, the results were astonishing that the Moringa leaves extract has radically changed the $\mathrm{Hb}$ response to all the parameters, putting forward bigger questions: how did this happen? What sort of reactions could have taken place between the $\mathrm{Hb}$ molecule and the natural supplement used?.... etc. in other words, one can expect a change in the behavior of the cell in response to the natural supplement as the cell contains the factory where the workers, as enzymes, and the compartment is available for antioxidants, metabolites, ... and proteins provided by the natural supplement to be used in repair processes. On the other hand, $\mathrm{Hb}$ is only a molecule that has none of these facilities then; how can it be affected in such a way?

\subsection{Mortality rate.}

It worthies mentioning that the use of Moringa leaves extract it was noticed that mortality reached eight rats in the HDR group out of forty, while the LDR group has only 2 dead rats during the experiment time of one month. Comparing to reference [40] were two other groups exposed to the same dose rates and total dose but didn't have Moringa leaves extract, the LDR group had the same mortality rate, while the HDR group had 18 dead rats out of forty in the absence of Moringa leaves extract. In other words, Moringa leaves extract reduced the number of dead rats from 18 to 8 rats out of forty rats exposed to HDR. There was no noticeable effect in the case of LDR exposure.

\section{Conclusions}

This work shows that permittivity and free energy had different behaviors for LDR and HDR groups. Internal energy and entropy displayed contradicting behavior for LDR and HDR groups as well. Moreover, data indicate that Moringa leaves extract had a powerful effect that could help the " system" repair mechanisms against radiation damage. Also, comparing results to that found in [29, 40], it could be concluded that the administration of Moringa leaves extract 
can change the biosystem response, which implies that more researchers from other eras to estimate the proper extract dose that can reduce radiation injuries to a minimum and at the same time would not be too strong on the biosystem. Finally, it is clear that dielectric parameters and related thermodynamic state functions provided good sensitivity toward using the living organisms to the Moringa leaves extract's components to repair radiation injuries. This is reflected in reversing the $\mathrm{Hb}$ response to high dose rates for most of the parameters used compared to rats' response to the same dose rates without feeding the Moringa leaves extract.

Based on this work and our other published papers, the use of radiation dose rate should be chosen carefully based on the biosystem's response under investigation to achieve maximum benefit.

\section{Funding}

This research received no external funding.

\section{Acknowledgments}

The authors would like to thank the STDF project number 2238 for the financial support to buy the impedance analyzer (E4991B), KeySight Instrument.

\section{Conflicts of Interest}

The authors declare no conflict of interest.

\section{References}

1 Gopalakrishnan, L.; Doriya, K.; Kumar, D.S. Moringa oleifera: A review on nutritive importance and its medicinal application. Food Science and Human Wellness 2016, 5, 49-56, https://doi.org/10.1016/j.fshw.2016.04.001.

2 Taher, M. Moringa oleifera (Shajna): the wonderful indigenous medicinal plant. Asian Journal of Medical and Biological Research 2017, 3, 20-30, https://doi.org/10.3329/ajmbr.v3i1.32032.

3 Lalas, S.; Athanasiadis, V.; Karageorgou, I.; Batra, G.; Nanos, G.D.; Makris, D.P. Nutritional Characterization of Leaves and Herbal Tea of Moringa oleifera Cultivated in Greece. Journal of Herbs, Spices \& Medicinal Plants 2017, 23, 320-333, https://doi.org/10.1080/10496475.2017.1334163.

4 Salmerón-Manzano, E.; Garrido-Cardenas, J.A.; Manzano-Agugliaro, F. Worldwide Research Trends on Medicinal Plants. International Journal of Environmental Research and Public Health 2020, 17, https://doi.org/10.3390/ijerph17103376.

5 Moyo, B.; Masika, P.J.; Hugo, A.; Muchenje, V. Nutritional characterization of Moringa (Moringa oleifera Lam.) leaves. African Journal Of Biotechnology 2011, 10, 12925-12933, https://doi.org/10.5897/AJB10.1599.

6 Nalamwar, R.R.; Raut, S.D.; Khan, N.D.; Khan, Z.H.; Mular, S.M. Nutritional assessment of Moringa oleifera leaves. International Journal of Applied Research 2017, 3, 411-413, http://dx.doi.org/10.22271/allresearch.

7 Nambiar, V.; Matela, H.; Baptist, A. Total antioxidant capacity using ferric reducing antioxidant power and 2, 2-diphenyl-1 picryl hydrazyl methods and phenolic composition of fresh and dried drumstick (Moringa oleifera) leaves. International Journal of Green Pharmacy 2013, 7, 66-72.

8 Chelliah, R.; Ramakrishnan, S.R.; Antony, U. Nutritional quality of Moringa oleifera for its bioactivity and antibacterial properties. International Food Research Journal 2017, 24, 825-833.

9 Welch, R.; Tietje, A. Investigation of Moringa oleifera leaf extract and its cancer-selective antiproliferative properties. Journal of the South Carolina Academy of Science 2017, 15, 8-13.

10 Omodanisi, E.I.; Aboua, Y.G.; Chegou, N.N.; Oguntibeju, O.O. Hepatoprotective, Antihyperlipidemic, and Anti-inflammatory Activity of Moringa oleifera in Diabetic-induced Damage in Male Wistar Rats. Pharmacognosy research 2017, 9, 182-187, https://doi.org/10.4103/0974-8490.204651.

11 Kou, X.; Li, B.; Olayanju, J.B.; Drake, J.M.; Chen, N. Nutraceutical or Pharmacological Potential of Moringa oleifera Lam. Nutrients 2018, 10, https://doi.org/10.3390/nu10030343. 
12 Sodvadiya, M.; Patel, H.; Mishra, A.; Nair, S. Emerging Insights into Anticancer Chemopreventive Activities of Nutraceutical Moringa oleifera: Molecular Mechanisms, Signal Transduction and In Vivo Efficacy. Current Pharmacology Reports 2020, 6, 38-51, https://doi.org/10.1007/s40495-020-00210-z.

13 Singh, D.; Arya, P.V.; Aggarwal, V.P.; Gupta, R.S. Evaluation of Antioxidant and Hepatoprotective Activities of Moringa oleifera Lam. Leaves in Carbon Tetrachloride-Intoxicated Rats. Antioxidants 2014, 3, 569-591, https://doi.org/10.3390/antiox3030569.

14 Vergara-Jimenez, M.; Almatrafi, M.M.; Fernandez, M.L. Bioactive Components in Moringa Oleifera Leaves Protect against Chronic Disease. Antioxidants 2017, 6, https://doi.org/10.3390/antiox6040091.

15 Mabrouki, L.; Rjeibi, I.; Taleb, J.; Zourgui, L. Cardiac Ameliorative Effect of Moringa oleifera Leaf Extract in High-Fat Diet-Induced Obesity in Rat Model. BioMed Research International 2020, 2020, https://doi.org/10.1155/2020/6583603.

16 Balakumbahan, R.; Sathiyamurthy, V.A.; Janavi, G.J. Moringa Leaf - A Super Food. Biotica Research Today 2020, 2, 438-440.

17 Chhikara, N.; Kaur, A.; Mann, S.; Garg, M.K.; Sofi, S.A.; Panghal, A. Bioactive compounds, associated health benefits and safety considerations of Moringa oleifera L.: an updated review. Nutrition \& Food Science 2020, 51, 255-277, https://doi.org/10.1108/NFS-03-2020-0087.

18 Hagoel, L.; Vexler, A.; Kalich-Philosoph, L.; Earon, G.; Ron, I.; Shtabsky, A.; Marmor, S.; Lev-Ari, S. Combined Effect of Moringa oleifera and Ionizing Radiation on Survival and Metastatic Activity of Pancreatic Cancer Cells. Integrative Cancer Therapies 2019, 18, 1-11, https://doi.org/10.1177/1534735419828829.

19 Kaur, S.; Panghal, A.; Garg, M.K.; Mann, S.; Khatkar, S.K.; Sharma, P.; Chhikara, N. Functional and nutraceutical properties of pumpkin - a review. Nutrition \& Food Science 2019, 50, 384-401, https://doi.org/10.1108/NFS-05-2019-0143.

20 Adefegha, S.A.; Oboh, G.; Iyoha, A.E.; Oyagbemi, A.A. Comparative effects of horseradish (Moringa oleifera) leaves and seeds on blood pressure and crucial enzymes relevant to hypertension in rat. PharmaNutrition 2019, 9, https://doi.org/10.1016/j.phanu.2019.100152.

21 Rao, A.V.; Devi, P.U.; Kamath, R. In vivo radioprotective effect of Moringa oleifera leaves. Indian journal of experimental biology 2001, 39, 858-863.

22 Arora, R.; Gupta, D.; Chawla, R.; Sagar, R.; Sharma, A.; Kumar, R.; Prasad, J.; Singh, S.; Samanta, N.; Sharma, R.K. Radioprotection by plant products: present status and future prospects. Phytotherapy Research 2005, 19, 1-22, https://doi.org/10.1002/ptr.1605.

23 Bhandari, P. A review of radioprotective plants. International Journal of Green Pharmacy 2013, 7, 90-101.

24 Elwan, A.M.; Salama, A.A.; Sayed, A.M.; Ghoneim, A.M.; Elsaied, A.A.; Ibrahim, F.A.; Elnasharty, M.M.M. Biophysical and biochemical roles of Moringa oleifera leaves as radioprotector. Progress in Biophysics and Molecular Biology 2018, 140, 142-149, https://doi.org/10.1016/j.pbiomolbio.2018.06.003.

25 Ocolotobiche, E.E.; Banegas, Y.C.; Güerci, A.M. Modulation of ionizing radiation-induced damage in human blood lymphocytes by in vivo treatment with resveratrol. International Journal of Radiation Biology 2019, 95, 1220-1225, https://doi.org/10.1080/09553002.2019.1625489.

26 Ramadan, R.; Vromans, E.; Anang, D.C.; Decrock, E.; Mysara, M.; Monsieurs, P.; Baatout, S.; Leybaert, L.; Aerts, A. Single and fractionated ionizing radiation induce alterations in endothelial connexin expression and channel function. Scientific Reports 2019, 9, https://doi.org/10.1038/s41598-019-39317-9.

27 Hall, E.J.; Giaccia, A.J. Chapter 5-Radiobiology for the Radiologist. In: Fractionated Radiation and the Dose-Rate Effect. 7th ed., Wolters Kluwer Health/Lippincott Williams \& Wilkins, Philadelphia, 2012; pp. 67-85, https://doi.org/10.1007/978-3-319-31341-2.

28 Brooks, A.L.; Hoel, D.G.; Preston, R.J. The role of dose rate in radiation cancer risk: evaluating the effect of dose rate at the molecular, cellular and tissue levels using key events in critical pathways following exposure to low LET radiation. International Journal of Radiation Biology 2016, 92, 405-426, https://doi.org/10.1080/09553002.2016.1186301.

29 Elnasharty, M.M.M.; Elwan, A.M. Estimation of radiation dose "'rates' changes on Hb using dielectric parameters. Arab Journal of Basic and Applied Sciences 2019, 26, 236-241, https://doi.org/10.1080/25765299.2019.1607996.

30 Elnasharty, M.M.; Elwan, A. Influence of Moringa Leaves Extract on the Response of Hb Molecule to Dose Rates' Changes: II.Relaxation Time and Its Thermodynamic Driven State Functions. World Academy of Science, Engineering and Technology International Journal of Medical and Health Sciences 2019, 13, 261265, https://doi.org/10.5281/zenodo.3298833.

31 Terashima, S.; Hosokawa, Y.; Tsuruga, E.; Mariya, Y.; Nakamura, T. Impact of time interval and dose rate on cell survival following low-dose fractionated exposures. Journal of Radiation Research 2017, 58, 782790, https://doi.org/10.1093/jrr/rrx025.

32 Elwan, A.M.; Salama, A.A.; Sayed, A.M.; Ghoneim, A.M.; Assaied, A.A.; Ibrahim, F.A.; Shousha, H.A.; Elnasharty, M.M.M. Response of rats to dose rates of ionizing radiation evaluated by dielectric properties of bone marrow. Progress in Biophysics and Molecular Biology 2018, 140, 124-132, https://doi.org/10.1016/j.pbiomolbio.2018.05.007. 
33 Olofsson, D.; Cheng, L.; Fernández, R.B.; Płódowska, M.; Riego, M.L.; Akuwudike, P.; Lisowska, H.; Lundholm, L.; Wojcik, A. Biological effectiveness of very high gamma dose rate and its implication for radiological protection. Radiation and Environmental Biophysics 2020, 59, 451-460, https://doi.org/10.1007/s00411-020-00852-z.

34 Hardison, R.C. A brief history of hemoglobins: plant, animal, protist, and bacteria. Proceedings of the National Academy of Sciences 1996, 93, 5675-79, https://doi.org/10.1073/pnas.93.12.5675.

35 Dybas, J.; Bokamper, M.J.; Marzec, K.M.; Mak, P.J. Probing the structure-function relationship of hemoglobin in living human red blood cells. Spectrochimica Acta Part A: Molecular and Biomolecular Spectroscopy 2020, 239, https://doi.org/10.1016/j.saa.2020.118530.

36 Debye, P. Polar molecules. Chemical Catalog Co. Inc., New York, USA. 1929; https://doi.org/10.1002/jctb.5000484320.

37 Fröhlich, H. Theory of Dielectrics. 2nd edn. Clarendon Press, Oxford. 1958

38 Nasir, N.; Al Ahmad, M. Cells Electrical Characterization: Dielectric Properties, Mixture, and Modeling Theories. Journal of Engineering 2020, 2020, https://doi.org/10.1155/2020/9475490.

39 Farsaci, F.; Tellone, E.; Galtieri, A.; Ficarra, S. Thermodynamics Characterization of Lung Carcinoma, Entropic Study and Metabolic Correlations. Fluids 2020, 5, https://doi.org/10.3390/fluids5040164.

40 Elnasharty, M.M.M.; Shousha, H.A.; Elwan, A.M. Permittivity, entropy, free and internal energies as tools for detecting radiation dose rates' changes in Hb. Progress in Biophysics and Molecular Biology 2018, 140, 74-78, https://doi.org/10.1016/j.pbiomolbio.2018.04.010.

41 Elnasharty, M.M.M.; Ghoneim, A.M.; Elwan, A.M. Dielectric and thermodynamic study of Hb exploring Moringa Oleifera leaves extract potential against radiation damage. Progress in Biophysics and Molecular Biology 2018, 140, 150-154, https://doi.org/10.1016/j.pbiomolbio.2018.06.004.

42 Świergiel, J.; Jadżyn, J. Static Dielectric Permittivity of Homologous Series of Liquid Cyclic Ethers, 3nCrown-n, $\mathrm{n}=4$ to 6. Journal of Chemical \& Engineering Data 2012, 57, 2271-2274, https://doi.org/10.1021/je300234g.

43 Jadżyn, J.; Świergiel, J. Odd-Even Effects in the Static Dielectric Permittivity of a Homologous Series of Liquid Cycloalkanones, $(\mathrm{CH} 2) \mathrm{n}-1 \mathrm{C}=\mathrm{O}, \mathrm{n}=4$ to 8. Journal of Chemical \& Engineering Data 2011, 56, 4715-4719, https://doi.org/10.1021/je200682t.

44 Jadżyn, J.; Czechowski, G. Prenematic Behavior of the Electric-Field-Induced Increment of the Basic Thermodynamic Quantities of Isotropic Mesogenic Liquids of Different Polarity. The Journal of Physical Chemistry B 2007, 111, 3727-3729, https://doi.org/10.1021/jp070569n.

45 Jadzyn, J.; Déjardin, J.; Czechowski G. Singular Pretransitional Behavior of the Electric Field-Dependent Part of the Thermodynamic Quantities of Strongly Polar Mesogenic Liquids in the Isotropic Phase. Acta Physica Polonica A 2007, 111, 877-884, https://doi.org/10.12693/APhysPolA.111.877.

46 Suhartono, S.; Ismail, Y.; Muhayya, S.; Husnah, M. Ethanolic extracts of Moringa oleifera leaves inhibit biofilm formation of Vibrio alginolyticus in vitro. IOP Conference Series: Earth and Environmental Science 2019, 348, https://doi.org/10.1088/1755-1315/348/1/012018.

47 Trivelli, L.A.; Ranney, H.M.; Lai, H.-T. Hemoglobin Components in Patients with Diabetes Mellitus. New England Journal of Medicine 1971, 284, 353-357, https://doi.org/10.1056/NEJM197102182840703. 